\title{
Outcomes following liver resection for multinodular Barcelona Clinic Liver Cancer-B hepatocellular carcinoma
}

\author{
SATOSHI MATSUKUMA ${ }^{1}$, KAZUHIKO SAKAMOTO ${ }^{1}$, YOSHIHIRO TOKUHISA ${ }^{1}$, YUKIO TOKUMITSU ${ }^{1}$, \\ HIROTO MATSUI $^{1}$, SHINSUKE KANEKIYO ${ }^{1}$, SHINOBU TOMOCHIKA ${ }^{1}$, MICHIHISA IIDA ${ }^{1}$, \\ NOBUAKI SUZUKI ${ }^{1}$, SHIGERU TAKEDA ${ }^{1}$, TOMIO UENO ${ }^{2}$, HIROSHI WADA ${ }^{3}$, SHOGO KOBAYASHI ${ }^{4}$, \\ ISSEI SAEKI ${ }^{5}$, HIDETOSHI EGUCHI ${ }^{4}$, MASATO SAKON $^{3}$, ISAO SAKAIDA ${ }^{5}$ and HIROAKI NAGANO ${ }^{1}$
}

\begin{abstract}
${ }^{1}$ Department of Gastroenterological, Breast and Endocrine Surgery, Yamaguchi University Graduate School of Medicine, Ube, Yamaguchi 755-8505; ${ }^{2}$ Department of Digestive Surgery, Kawasaki Medical School, Kurashiki, Okayama 701-0192; ${ }^{3}$ Department of Surgery, Osaka International Cancer Institute, Osaka 541-8567; ${ }^{4}$ Department of Gastroenterological Surgery, Osaka University Graduate School of Medicine, Suita, Osaka 565-0871; ${ }^{5}$ Department of Gastroenterology and Hepatology, Yamaguchi University Graduate School of Medicine, Ube, Yamaguchi 755-8505, Japan
\end{abstract}

Received March 12, 2018; Accepted August 30, 2018

DOI: $10.3892 / 01.2018 .9420$

\begin{abstract}
Management of multinodular hepatocellular carcinoma (HCC) in the intermediate Barcelona Clinic Liver Cancer (BCLC)-B stage is controversial. The aim of the present study as to identify the subgroup of patients with BCLC-B HCC who could benefit from liver resection. The present study retrospectively analyzed the outcomes of 65 patients (training cohort) who underwent liver resection for multinodular BCLC-B HCC. Cox's regression analysis was conducted to identify the independent prognostic factors for overall survival and to develop the prognostic score. As some authors have reported that maximum tumor size $(\mathrm{cm})$ plus tumor number $(\mathrm{N}+\mathrm{S})$ is a prognostic factor in patients with BCLC-B HCC who undergo chemoembolization, the usefulness of this factor in patients who underwent liver resection was also evaluated. Subsequently, the validity of the prognostic score was assessed in an independent validation cohort $(\mathrm{n}=132)$. Multivariate analysis revealed that positivity for hepatitis $\mathrm{C}$ virus antibody (HCV-ab), platelet count $\leq 10^{10} / 1, \mathrm{~N}+\mathrm{S}>8$, and des- $\gamma$-carboxy prothrombin (DCP) $>400 \mathrm{mAU} / \mathrm{ml}$ were independent prognostic factors for overall survival. The prognostic score differentiated two groups $(\leq 2, \geq 3)$ with distinct outcomes (median survival time 68.3 months vs. 29.1 months; $\mathrm{P}<0.0001$ ). This result was confirmed in an external validation cohort. Therefore, surgery
\end{abstract}

Correspondence to: Professor Hiroaki Nagano, Department of Gastroenterological, Breast and Endocrine Surgery, Yamaguchi University Graduate School of Medicine, 1-1-1 Minami-Kogushi, Ube, Yamaguchi 755-8505, Japan

E-mail: hnagano@yamaguchi-u.ac.jp

Key words: hepatocellular carcinoma, Barcelona Clinic Liver Cancer classification, intermediate stage, liver resection can promote long-term survival in patients with multinodular HCC although the indications for surgery are limited. HCV-Ab status, preoperative platelet count, DCP level and $\mathrm{N}+\mathrm{S}$ may be useful for patient selection.

\section{Introduction}

Hepatocellular carcinoma (HCC) is a major health concern, and the second leading cause of cancer-related death worldwide (1). Japanese surgeons have made significant contributions towards improvements in the surgery for HCC (2), and 7,000-8,000 patients per year undergo liver resection in Japan (3). Moreover, technical improvement in the safety of less invasive laparoscopic liver resection could change the practice of treatment for $\mathrm{HCC}(4,5)$. The Barcelona Clinic Liver Cancer (BCLC) classification, which is a staging system combining tumor status and liver function, has been widely endorsed by treatment guidelines for HCC in Western countries (6).

Multinodular HCC beyond the Milan criteria without vascular invasion is classified as intermediate in the BCLC classification (BCLC-B), and transarterial chemoembolization (TACE) is recommended as first-line therapy. However, several reports have suggested a survival benefit for liver resection over TACE in patients with HCC in BCLC-B (7-9), and liver resection for BCLC-B HCC patients has been actively performed, especially in Asian countries such as Japan. Since patients with BCLC-B HCC are a heterogeneous group (10), some may indeed benefit from liver resection compared with TACE. However, it is important to accurately identify this subgroup of patients.

Several groups have suggested prognostic factors after resection for BCLC-B HCC; however, many studies included large solitary tumors ( $\geq 5 \mathrm{~cm}$ in diameter) (11-15) and reported pathological factors such as microvascular invasion, tumor differentiation, and liver cirrhosis as prognostic factors $(12-14,16,17)$. Since it is difficult to curatively 
treat extremely large solitary tumors with TACE, complete resection is preferred and the indication for operative treatment is unequivocal. It is impossible to make decisions on the optimal therapy based solely on preoperative pathological factors. Therefore, we believe that studies about risk stratification of BCLC-B HCC should not include patients with solitary tumors and not use pathological factors as prognostic factors.

The purpose of this study was to derive a prognostic model of overall survival based on the pre-treatment tumor characteristics and patients' statuses, and to identify the subgroup of patients with multinodular HCC in BCLC-B who could benefit from liver resection.

\section{Patients and methods}

Patients. We retrospectively analyzed 65 patients (training cohort) with multinodular HCC classified as BCLC-B among the 447 HCC patients who underwent liver resection at Yamaguchi University Hospital (Yamaguchi, Japan) from January 2000 to December 2014 to derive a prognostic model. Next, the validity of the model was assessed in an independent external validation cohort $(n=132)$ that included 68 patients with multinodular HCC classified as BCLC-B among the 598 patients who underwent liver resection at Osaka University Hospital (Osaka, Japan) from May 1992 to December 2008, as well as 64 patients of 827 patients treated at Osaka International Cancer Institute (Osaka, Japan) from January 1990 to August 2013 in the validation cohort. Subsequently, we compared outcomes of patients with Child Pugh A who underwent liver resection in the training and validation cohorts $(n=186)$ with those of patients with Child Pugh A who underwent TACE at Yamaguchi University Hospital from May 1996 to December 2016 (n=93) (unpublished data).

HCC was diagnosed using contrast-enhanced computed tomography (CT) mainly with early enhancement in arterial phase followed by washout in the portal or late phases, and elevation of tumor markers, such as $\alpha$-fetoprotein (AFP) or des- $\gamma$-carboxy prothrombin (DCP). We included the patients with multinodular HCC in BCLC-B (2 or 3 nodules larger than $3 \mathrm{~cm}$, more than 4 lesions without macrovascular invasion) diagnosed preoperatively or intraoperatively.

The present study was approved by the Institutional Review Boards of each of the three institutes in which data was obtained (Yamaguchi University Hospital, Osaka International Cancer Institute and Osaka University Hospital; protocol no. H29-093) and was conducted in accordance with the ethical standards of the 1964 Declaration of Helsinki. The requirement for informed consent was waived as this was a retrospective cohort study.

Liver resection. The surgical indication for each patient was discussed at a multidisciplinary cancer board at each institute consisting of hepatopancreatobiliary surgeons, hepatologists, and medical oncologists. Residual liver volume were estimated by CT. Liver resection was carried out with or without the intermittent Pringle's maneuver (18) with intraoperative ultrasonographic guidance. Intraoperative radiofrequency thermal ablation (RFA) or microwave coagulation (MCT) with resection was performed in some patients.
Follow-up after liver resection. All patients were followed up in the outpatient clinic every 3 months after surgery with assessment of liver function and serum AFP and DCP levels. Enhanced CT or magnetic resonance images were obtained every 3-4 months and further studies with bone scintigraphy or positron emission tomography were performed when extrahepatic recurrence was suspected. For patients with recurrence, TACE, locoregional therapy, liver resection, or systemic chemotherapy with sorafenib were administered depending on tumor spread and liver function.

Statistical analysis. Categorical variables are presented as numbers and were analyzed by using Fisher exact test or chi-square test as appropriate. Continuous variables are presented as medians and ranges and were compared by using the Mann-Whitney U test. The Kaplan-Meier method was used to calculate recurrence-free and overall survival, and differences were evaluated using the log-rank test. Independent prognostic factors for overall survival were analyzed with the Cox's proportional hazard regression model in a stepwise manner. Statistical analyses were performed using Statflex ver. 6 (Artec, Osaka, Japan), and $\mathrm{P}<0.05$ was considered to indicate a statistically significant difference.

\section{Results}

Characteristics of patients in the training cohort. The median follow-up period after surgery was 37.4 months (range, 4-187 months). The clinicopathologic characteristics of the 65 patients (51 men, 14 women) are shown in Table I. The median age was 68 years old (range, $35-83$ years old). Laboratory results showed that 13 patients were positive for hepatitis B virus surface antigen (HBs-Ag), and 42 had antibodies for hepatitis $\mathrm{C}$ virus (HCV-Ab). The median preoperative serum AFP and DCP was $32 \mathrm{ng} / \mathrm{ml}$ (range, $0.8-239621 \mathrm{ng} / \mathrm{ml}$ ) and $160 \mathrm{mAU} / \mathrm{ml}$ (range, 12-71200 $\mathrm{mAU} / \mathrm{ml})$, respectively.

The median tumor diameter and number was $4 \mathrm{~cm}$ (range, 1.5-17 cm) and 3 (range 2-uncountable), respectively. Tumors in 13 patients were limited to 1 section, those in 27 patients involved 2 sections, those in 18 patients involved 3 sections and those in 7 patients were involved to 4 sections, and 35 patients $(53.8 \%)$ had bilobar disease.

Of the 11 patients who underwent pre-operative therapy, 9 underwent TACE and 2 underwent intra-arterial chemotherapy with 5-flurouracil and cisplatin. The response to pre-operative therapy was unsatisfactory in all patients; 2 patients had stable disease while there was disease progression in 9 patients.

Partial resection was performed in 23 patients, segmentectomy in 15 , sectionectomy in 9 , hemihepatectomy or bisectionectomy in 16, and trisectionectomy in 2. Liver resection with RFA or MCT was performed in 21 patients.

Curative resection without residual tumor was performed in 49 patients and palliative resection with residual tumor in 16 patients.

Postoperative survival and recurrence in the training cohort. The 1-, 3-, and 5-year overall survival rates of all 
Table I. Clinicopathological characteristics and overall survival of the 65 patients in the training cohort.

\begin{tabular}{|c|c|c|c|c|c|}
\hline Variable & $\mathrm{n}$ & 1-year & 3-year & 5-year & P-value \\
\hline \multicolumn{6}{|l|}{ Age, years } \\
\hline$<68$ & 29 & 93.1 & 61.7 & 51.7 & \multirow[t]{2}{*}{0.4897} \\
\hline$\geq 68$ & 36 & 97.1 & 72.4 & 40.1 & \\
\hline \multicolumn{6}{|l|}{ Sex } \\
\hline Male & 51 & 93.9 & 67.7 & 47.8 & \multirow[t]{2}{*}{0.0929} \\
\hline Female & 14 & 100 & 67.1 & 28 & \\
\hline \multicolumn{6}{|l|}{ HBs-Ag } \\
\hline Negative & 52 & 98 & 69.4 & 44 & \multirow[t]{2}{*}{0.4595} \\
\hline Positive & 13 & 84.6 & 60.6 & 50.5 & \\
\hline \multicolumn{6}{|l|}{$\mathrm{HCV}-\mathrm{Ab}$} \\
\hline Negative & 23 & 90.9 & 72.1 & 65.6 & \multirow[t]{2}{*}{0.3263} \\
\hline Positive & 42 & 97.5 & 65.3 & 35 & \\
\hline \multicolumn{6}{|c|}{ Prothrombin rate, $\%$} \\
\hline$\leq 70$ & 3 & 100 & 66.7 & 33.3 & \multirow[t]{2}{*}{0.2581} \\
\hline$>70$ & 62 & 95 & 67.6 & 45.4 & \\
\hline \multicolumn{6}{|c|}{ Albumin level, g/dl } \\
\hline$\leq 3.5$ & 24 & 91.3 & 64.1 & 29.4 & \multirow[t]{2}{*}{0.1551} \\
\hline$>3.5$ & 41 & 97.4 & 69.5 & 53.1 & \\
\hline \multicolumn{6}{|c|}{ Platelet count, / $\mu 1$} \\
\hline$\leq 1.0 \times 10^{5}$ & 18 & 94.1 & 41.2 & 11.8 & \multirow[t]{2}{*}{0.0001} \\
\hline$>1.0 \times 10^{5}$ & 47 & 95.6 & 78.4 & 59.9 & \\
\hline \multicolumn{6}{|l|}{ ICGR $15, \%$} \\
\hline$<15$ & 28 & 96.3 & 76.8 & 53.3 & \multirow[t]{2}{*}{0.1811} \\
\hline$\geq 15$ & 37 & 94.4 & 60.7 & 38.7 & \\
\hline \multicolumn{6}{|l|}{ Child-Pugh } \\
\hline 5 & 37 & 97.1 & 68.6 & 53.4 & \multirow[t]{3}{*}{0.0873} \\
\hline 6 & 27 & 92.3 & 68.4 & 34.6 & \\
\hline 7 & 1 & 100 & 0 & 0 & \\
\hline \multicolumn{6}{|c|}{ Tumor size on image, $\mathrm{cm}$} \\
\hline$<5$ & 45 & 100 & 74.9 & 54.4 & \multirow[t]{2}{*}{0.0563} \\
\hline$\geq 5$ & 20 & 85 & 52.2 & 22.4 & \\
\hline \multicolumn{6}{|c|}{ Number of tumors on image } \\
\hline 2 & 25 & 100 & 73.1 & 48.8 & 0.1636 \\
\hline$\geq 3$ & 40 & 92.4 & 64.4 & 42.8 & \\
\hline Tumor size & & & & & \\
\hline$\leq 8$ & 42 & 100 & 78.3 & 50.9 & 0.0415 \\
\hline$>8$ & 23 & 87 & 49 & 35 & \\
\hline Liver cirrh & & & & & \\
\hline Absent & 31 & 93.3 & 79.4 & 54.3 & 0.0307 \\
\hline Present & 34 & 97 & 56.1 & 35.6 & \\
\hline AFP, $\mathrm{ng} / \mathrm{ml}$ & & & & & \\
\hline$<400$ & 50 & 97.9 & 70.2 & 45.2 & 0.5982 \\
\hline$\geq 400$ & 15 & 86.7 & 59.3 & 42.3 & \\
\hline $\mathrm{DCP}, \mathrm{mAU}$ & & & & & \\
\hline$<400$ & 39 & 100 & 78 & 58.6 & 0.0047 \\
\hline$\geq 400$ & 26 & 88.5 & 53.1 & 27.2 & \\
\hline Bilobar dis & & & & & \\
\hline No & 30 & 100 & 69.4 & 39 & 0.9002 \\
\hline Yes & 35 & 91.3 & 66.2 & 50.7 & \\
\hline
\end{tabular}


Table I. Continued.

\begin{tabular}{|c|c|c|c|c|c|}
\hline Variable & $\mathrm{n}$ & 1-year & 3-year & 5-year & P-value \\
\hline \multicolumn{6}{|l|}{ Histologic grade } \\
\hline Well-moderate & 57 & 94.5 & 64.4 & 42 & \multirow[t]{2}{*}{0.9984} \\
\hline Poor & 8 & 100 & 87.5 & 62.5 & \\
\hline \multicolumn{6}{|c|}{ Microscopic vascular invasion } \\
\hline Absent & 33 & 100 & 79.4 & 61.2 & \multirow[t]{2}{*}{0.0400} \\
\hline Present & 32 & 90.2 & 56 & 30.2 & \\
\hline \multicolumn{6}{|c|}{ Intrahepatic metastasis } \\
\hline Absent & 35 & 97 & 70 & 46.4 & \multirow[t]{2}{*}{0.3759} \\
\hline Present & 30 & 93.3 & 65.7 & 43.7 & \\
\hline \multicolumn{6}{|l|}{ Residual tumor } \\
\hline Absent & 49 & 97.8 & 66.8 & 47.6 & \multirow[t]{2}{*}{0.0590} \\
\hline Present & 16 & 87.5 & 68.8 & 35.7 & \\
\hline \multicolumn{6}{|c|}{ Preoperative therapy } \\
\hline No & 53 & 96.1 & 70.9 & 47.5 & \multirow[t]{2}{*}{0.1821} \\
\hline Yes & 11 & 90.9 & 54.6 & 34.1 & \\
\hline
\end{tabular}

HBs-Ag, hepatitis B surface antigen; HCV-Ab, hepatitis C virus antibody; ICGR, indocyanine green retention rate at 15 min; AFP, $\alpha$-fetoprotein; DCP, des- $\gamma$-carboxy prothrombin.

65 patients was $95.2,67.6$, and $44.8 \%$, respectively (Fig. 1A). The median survival was 51.0 months and 35 patients died in the follow-up period. Cancer progression $(n=19,54.3 \%)$ was the most frequent cause of death, followed by other diseases $(n=8,22.9 \%)$, liver failure $(n=4,11.4 \%)$, rupture of varices $(n=1,2.9 \%)$, and unknown causes $(n=3,8.6 \%)$. The $1-$, 3 -, and 5-year recurrence-free survival rate of the 49 patients without residual tumor was $70.5,28.0$, and $22.1 \%$, respectively (Fig. 1B).

Univariate analysis showed liver cirrhosis and microscopic vascular invasion $(\mathrm{mVI})$ to be associated with poorer survival, while tumors $>5 \mathrm{~cm}$, tumor numbers $>3$, bilobar disease, and palliative operations with residual tumors were not (Table I).

Next, we analyzed the relationship between overall survival and the sum of the largest tumor's diameter and the number of tumors $(\mathrm{N}+\mathrm{S})$. The overall survival of patients with $\mathrm{N}+\mathrm{S} \leq 8$ was significantly better than that of patient with $\mathrm{N}+\mathrm{S}>8$.

Cox's regression analysis was used to assess the relationship between pre-operative factors and overall survival with stepwise backward elimination. The following variables were included in the Cox's proportional model: age ( $\geq 68$ vs. $<68$ years), sex, preoperative therapy (no vs. yes), positivity for $\mathrm{HBs}-\mathrm{Ag}$, positivity for $\mathrm{HCV}-\mathrm{Ab}$, albumin level (>3.5 g/dl vs. $\leq 3.5 \mathrm{~g} / \mathrm{dl}$ ), prothrombin rate (>70\% vs. $\leq 70 \%)$, platelet count (Plt; $>1.0 \times 10^{10} / 1$ vs. $\left.\leq 1.0 \times 10^{10} / 1\right)$, indocyanine green retention rate at $15 \mathrm{~min}(\geq 15 \%$ vs. $<15 \%)$, tumor size on imaging ( $\geq 5 \mathrm{~cm}$ vs. $<5 \mathrm{~cm}$ ), number of tumors on imaging ( $\geq 3$ vs. $<3$ ), N+S (>8 vs. $\leq 8$ ), bilobar disease (no vs. yes), and $\mathrm{DCP}(\geq 400 \mathrm{mAU} / \mathrm{ml}$ vs. $<400 \mathrm{mAU} / \mathrm{ml}$ ). Multivariate analysis revealed that positivity for $\mathrm{HCV}-\mathrm{Ab}, \mathrm{Plt} \leq 1.0 \times 10^{10} / 1, \mathrm{~N}+\mathrm{S}>8$, and DCP $>400 \mathrm{mAU} / \mathrm{ml}$ were independent prognostic factors for overall survival (Table II).
Table II. Multivariable Cox-regression analysis of overall survival.

\begin{tabular}{lccc}
\hline Variable & RR & $95 \%$ CI & P-value \\
\hline $\begin{array}{l}\text { HCV-Ab } \\
\text { Negative }\end{array}$ & 1 & & \\
Positive & 3.193 & $1.274-8.000$ & 0.0132 \\
Platelet count, $/ \mu 1$ & & & \\
$\leq 1.0 \times 10^{5}$ & 1 & & \\
$>1.0 \times 10^{5}$ & 3.785 & $1.764-8.121$ & 0.0006 \\
N+S & & & \\
$\leq 8$ & 1 & & 0.0011 \\
$>8$ & 3.614 & $1.670-7.820$ & \\
DCP, mAU/ml & & & 0.0011 \\
$\leq 400$ & 1 & & \\
$>400$ & 3.556 & $1.664-7.599$ &
\end{tabular}

$\mathrm{RR}$, relative risk; $\mathrm{CI}$, confidence interval; $\mathrm{HCV}-\mathrm{Ab}$, hepatitis $\mathrm{C}$ virus antibody; N+S, sum of largest tumor diameter $(\mathrm{cm})$ and number of tumors; DCP, des- $\gamma$-carboxy prothrombin.

Prognostic score and overall survival in the training cohort. Subsequently, we allocated 1 point to each prognostic factor, calculated the score for each patient by summing their points, and analyzed the effect of the score on overall survival. The 1-, 3-, and 5-year overall rate and median survival of patients with a score of $0(n=6)$ were $100,80,80 \%$, and over 10 years (not reached), respectively; for those with a score of $1(n=25)$, they were $100,90.5,79.5 \%$, and 102.1 months; for those with a score of $2(n=19)$, they were $94.4,72.2,33.1 \%$, and 51.0 months; 

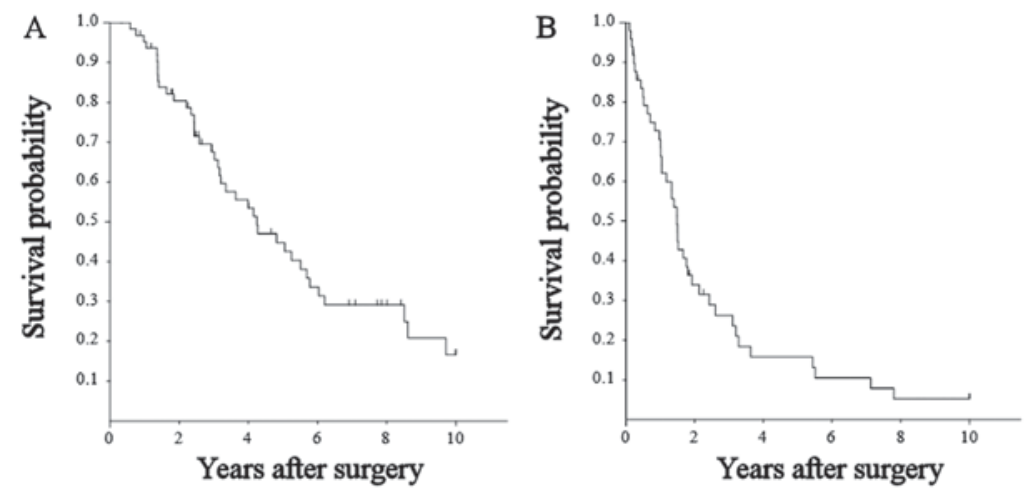

Figure 1. Overall and disease-free survival following liver resection in patients with Barcelona Clinic Liver Cancer-B hepatocellular carcinoma in training cohort. (A) Overall survival of 65 patients who underwent liver resection. (B) Disease-free survival of 49 patients who underwent liver resection without residual tumor.
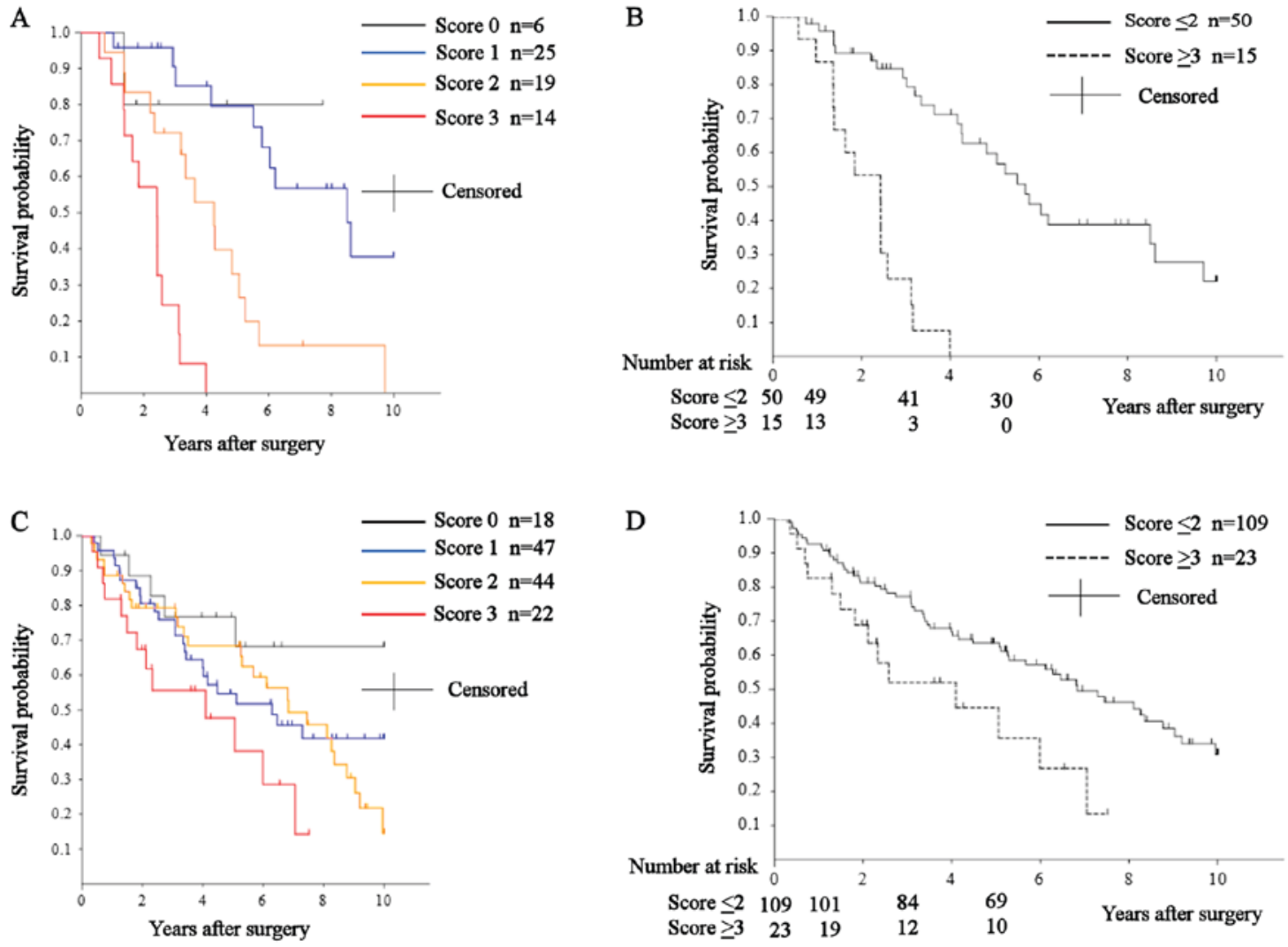

Figure 2. Overall survival following liver resection based on the prognostic score. (A) The surgical outcome of patients in the training cohort based on the prognostic score. The overall survival of patients with a score of 1 (blue line) was significantly better than those with a score of 2 (orange line, $\mathrm{P}=0.0001$ ) or 3 (red line, $\mathrm{P}<0.0001)$, and those who scored 2 fared significantly better than those who scored $3(\mathrm{P}=0.0255)$. (B) The surgical outcome of the two groups of patients (score $\leq 2 \mathrm{vs} . \geq 3$ ) in the training cohort. Overall survival of patients with a score $\leq 2$ (solid black line) was significantly better than those with a score $\geq 3$ (dotted line; $\mathrm{P}<0.0001$ ). (C) The surgical outcome of patients in the validation cohort based on our prognostic score. The overall survival of patients with a score of 0 (black line) was significantly better than those with a score of 3 (red line, $P=0.0243$ ). (D) The surgical outcome of the two groups of patients (score $\leq 2$ vs. $\geq 3$ ) in the validation cohort. Overall survival of patients with a score $\leq 2$ (solid black line) was significantly better than those with a score $\geq 3$ (dotted line; $\mathrm{P}=0.0164)$.

for those with a score of $3(n=14)$, they were $85.7,24.5,0 \%$, and 29.1 months; and for those with a score of $4(n=1)$, they were 100, 0, 0\%, and not available (Fig. 2A). The overall survival of patients with a score of 0 was significantly better than those with a score of $3(\mathrm{P}=0.0318)$. Overall survival in those with a score of 1 was significantly better than in those with scores of 2 and $3(\mathrm{P}=0.0014$ and $\mathrm{P}<0.0001$, respectively). Patients with a score of 2 had significantly better overall survival than those with a score of $3(\mathrm{P}=0.0021)$. Using a cutoff point of 2 , we classified the patients into two groups: score $\leq 2(n=50)$ and score $\geq 3$ $(\mathrm{n}=15)$. The 1-,3-, and 5-year overall rates and median survival of patients in the score $\leq 2$ group were 97.9, 82.0, 59.7\%, and 68.3 months, respectively. In the score $\geq 3$ group, they were 86.7, 22.9, 0\%, and 29.1 months, respectively (Fig. 2B). Overall survival in the score $\leq 2$ group was significantly better than in the score $\geq 3$ group $(\mathrm{P}<0.0001)$. 
Table III. Clinicopathological characteristics and overall survival in the 132 patients of the validation cohort.

\begin{tabular}{|c|c|c|c|c|c|}
\hline Variable & $\mathrm{n}$ & 1-year & 3-year & 5-year & P-value \\
\hline \multicolumn{6}{|l|}{ Age, years } \\
\hline$<68$ & 84 & 91.7 & 74.2 & 60.7 & \multirow[t]{2}{*}{0.9019} \\
\hline$\geq 68$ & 48 & 89.6 & 71.4 & 60.4 & \\
\hline \multicolumn{6}{|l|}{ Sex } \\
\hline Male & 110 & 92.7 & 73.4 & 60.9 & \multirow[t]{2}{*}{0.7961} \\
\hline Female & 22 & 81.8 & 71.8 & 59.8 & \\
\hline \multicolumn{6}{|l|}{ HBs-Ag } \\
\hline Negative & 104 & 91.4 & 76.9 & 60.7 & \multirow[t]{2}{*}{0.4944} \\
\hline Positive & 28 & 89.3 & 59.4 & 59.4 & \\
\hline \multicolumn{6}{|l|}{$\mathrm{HCV}-\mathrm{Ab}$} \\
\hline Negative & 56 & 89.3 & 66.7 & 56.3 & \multirow[t]{2}{*}{0.8623} \\
\hline Positive & 76 & 92.1 & 77.9 & 63.5 & \\
\hline \multicolumn{6}{|c|}{ Prothrombin rate, $\%$} \\
\hline$\leq 70$ & 21 & 90.5 & 65.2 & 54.3 & \multirow[t]{2}{*}{0.6857} \\
\hline$>70$ & 111 & 91 & 74.7 & 61.8 & \\
\hline \multicolumn{6}{|c|}{ Albumin level, g/dl } \\
\hline$\leq 3.5$ & 40 & 85 & 71.5 & 52.2 & \multirow[t]{2}{*}{0.2968} \\
\hline$>3.5$ & 92 & 93.5 & 74 & 63.9 & \\
\hline \multicolumn{6}{|l|}{ Platelet count, $/ \mu 1$} \\
\hline$\leq 1.0 \times 10^{5}$ & 19 & 89.5 & 69.8 & 69.8 & \multirow{2}{*}{0.9496} \\
\hline$>1.0 \times 10^{5}$ & 113 & 91.2 & 73.7 & 59.6 & \\
\hline \multicolumn{6}{|l|}{ ICGR15, \% } \\
\hline$<15$ & 75 & 90.7 & 75.2 & 68.7 & \multirow[t]{2}{*}{0.0095} \\
\hline$\geq 15$ & 57 & 91.2 & 70.7 & 50 & \\
\hline \multicolumn{6}{|l|}{ Child-Pugh } \\
\hline 5 & 83 & 92.8 & 73.5 & 63.6 & \multirow[t]{3}{*}{$>0.5$} \\
\hline 6 & 39 & 89.7 & 73.8 & 55.6 & \\
\hline 7 & 10 & 80 & 68.6 & 54.9 & \\
\hline \multicolumn{6}{|c|}{ Tumor size on image, $\mathrm{cm}$} \\
\hline$<5$ & 67 & 94 & 84.1 & 69.4 & \multirow[t]{2}{*}{0.0462} \\
\hline$\geq 5$ & 65 & 87.7 & 62.2 & 51.5 & \\
\hline \multicolumn{6}{|c|}{ Number of tumor on image } \\
\hline 2 & 89 & 93.3 & 78.2 & 66.7 & 0.0447 \\
\hline$\geq 3$ & 43 & 86.1 & 62.2 & 46.3 & \\
\hline Tumor size + nur & & & & & \\
\hline$\leq 8$ & 85 & 96.5 & 84 & 68.8 & 0.0005 \\
\hline$>8$ & 47 & 80.9 & 53.1 & 45 & \\
\hline AFP, ng/ml & & & & & \\
\hline$<400$ & 106 & 93.4 & 77.5 & 63.4 & 0.1945 \\
\hline$\geq 400$ & 26 & 80.8 & 55.5 & 49.9 & \\
\hline $\mathrm{DCP}, \mathrm{mAU} / \mathrm{ml}$ & & & & & \\
\hline$<400$ & 69 & 92.8 & 75.6 & 65 & 0.171 \\
\hline$\geq 400$ & 63 & 88.9 & 70.7 & 55.9 & \\
\hline Histologic grade & & & & & \\
\hline Well-moderate & 91 & 95.6 & 75.7 & 63.9 & 0.6236 \\
\hline Poor & 41 & 80.5 & 67.6 & 53.1 & \\
\hline Microscopic vas & & & & & \\
\hline Absent & 84 & 94.1 & 76.6 & 65.6 & 0.1604 \\
\hline Present & 48 & 85.4 & 67.2 & 51.6 & \\
\hline
\end{tabular}

HBs-Ag, hepatitis B surface antigen; HCV-Ab, hepatitis C virus antibody; ICGR, indocyanine green retention rate at 15 min; AFP, a-fetoprotein; DCP, des- $\gamma$-carboxy prothrombin. 


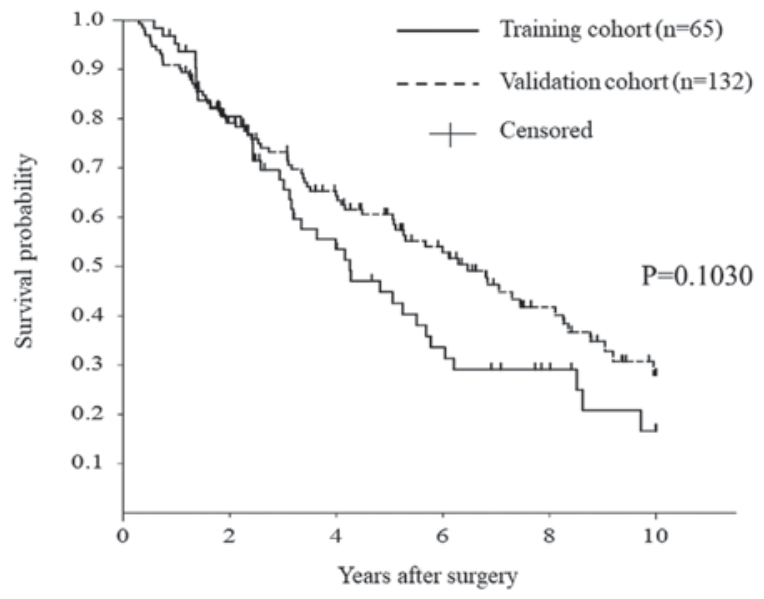

Figure 3. Overall survival following liver resection in the training and validation cohorts.

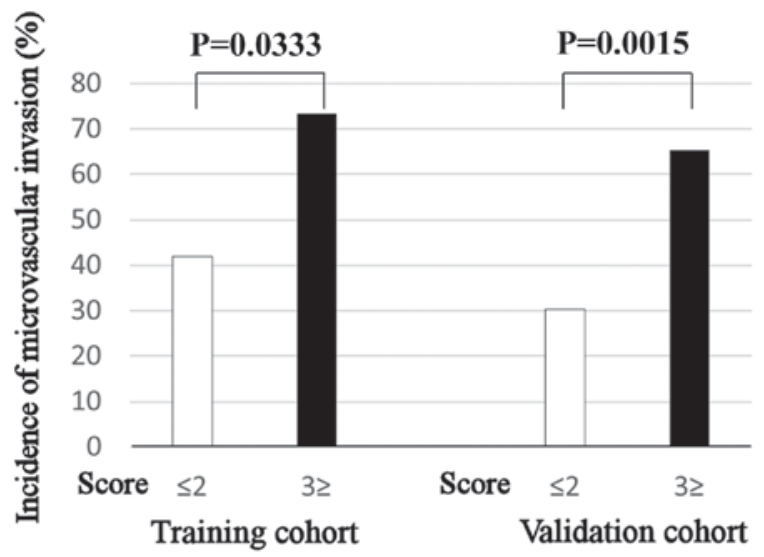

Figure 4. Correlation between the prognostic score and incidence of microvascular invasion in the training and validation cohorts. The incidence of microvascular invasion in patients with a score $\geq 3$ was significantly higher than in those with a score $\leq 2$ in each cohort.

Prognostic score and overall survival in the validation cohort. The clinicopathological characteristics of the 132 patients in the validation cohort are shown in Table III. The median follow-up period after surgery was 49.8 months (range, 3.6-201 months). The median age was 65 (range, 31-84) years. The median of preoperative serum AFP and DCP was $28.5 \mathrm{ng} / \mathrm{ml}$ (range, $1-33268 \mathrm{ng} / \mathrm{ml}$ ) and $326 \mathrm{mAU} / \mathrm{ml}$ (range, $10-357456 \mathrm{mAU} / \mathrm{ml}) \mathrm{mAU} / \mathrm{ml}$, respectively.

The median tumor diameter and number of tumors was $4.6 \mathrm{~cm}$ (range, 1.6-17 cm) and 2 (range, 2-uncountable), respectively.

Partial resection was performed in 44, segmentectomy in 16 , sectionectomy in 9 , hemihepatectomy or bisectionectomy in 42 , and trisectionectomy in 30 .

The 1-, 3-, and 5-year overall rates and median survival of patients in the validation cohort were 97.0, 75.8, 60.5\%, and 77.5 months, respectively. A total of 73 patients died during the follow-up period. Cancer progression $(n=60$, $82.2 \%$ ) was the most frequent cause of death, followed by other diseases $(n=4,5.5 \%)$, liver failure $(n=1,1.4 \%)$, and unknown causes $(n=8,11.0 \%)$. There was no difference in overall survival between the training and validation cohorts (Fig. 3; $\mathrm{P}=0.1030$ ).
The 1-, 3-, and 5-year overall rates and median survival of patients with a score of $0(n=18)$ were $94.4,76.7,76.7 \%$, and over 10 years (not reached), respectively. For those with a score of $1(\mathrm{n}=47)$, they were $95.7,75.9,54.6 \%$, and 75.5 months. For those with a score of $2(n=44)$, they were $88.6,79.3,68.4 \%$, and 82.0 months. For those with a score of $3(n=22)$, they were $81.8,55.6,47.7 \%$, and 49.2 months. For those with a score of $4(n=1)$, they were $100,0,0 \%$, and not available (Fig. 2C). Overall survival in patients with a score of 0 was significantly better than in those with a score of 3 $(\mathrm{P}=0.0243)$.

Similar to our approach in the training cohort, patients were classified into two groups: Score $\leq 2(n=109)$ and score $\geq 3$ $(\mathrm{n}=23)$. The 1-, 3-, and 5-year overall rates and median survival of patients in the score $\leq 2$ group were 92.7, 77.3, 63.5\%, and 82.0 months, respectively. For those in the score $\geq 3$ group, they were 82.6, 52.0, 44.6\%, and 49.2 months (Fig. 2D). Overall survival in the $\leq 2$ group was significantly better than that in the $\geq 3$ group $(\mathrm{P}=0.0164)$.

Relationship between prognostic score and microvascular invasion. In the training cohort, the incidence of $\mathrm{mVI}$ in patients with a score $\geq 3(73.3 \%)$ was significantly higher than in those with a score $\leq 2(42.0 \% ; \mathrm{P}=0.0333)$. Similarly, the incidence of $\mathrm{mVI}$ in patients with a score $\geq 3(65.2 \%)$ was significantly higher than in those with a score $\leq 2(30.3 \%$; $\mathrm{P}=0.0015$ ) in the validation cohort (Fig. 4).

Survival in each subgroup according to treatment modality. Finally, we compared the overall survival of patients with Child-Pugh $\mathrm{A}$ in the training and validation cohorts who underwent surgery $(n=186)$ with those of patients with Child-Pugh A who underwent TACE ( $\mathrm{n}=93$ ) (unpublished data). The clinicopathological characteristics of patients in each group are shown in Table IV. Although the ratio of males to females (surgery: 153 males to 33 females; TACE: 69 males to 24 females; $\mathrm{P}=0.1153$ ) and positivity of $\mathrm{HCV}-\mathrm{Ab}$ (surgery: 114; TACE: 58; $\mathrm{P}=0.8618$ ) were not different, the median age was older in the TACE group [surgery: 66.0 (range, 31.0-84.0); TACE: 74.2 (range, 48.2-87.8); $\mathrm{P}<0.0001]$. Although the median tumor diameter was larger in the surgery group [surgery: $4.5 \mathrm{~cm}$ (range, 1.5-17.0); TACE: $3.7 \mathrm{~cm}$ (range, 1.0-8.9); $\mathrm{P}=0.0002]$ and the median of number of tumors was larger in the TACE group [surgery: 2 (range, 2-uncountable); TACE: 4 (range, 2-11); $\mathrm{P}<0.0001$ ], the proportion of $\mathrm{N}+\mathrm{S}>8$ in each group (surgery: 64; TACE: 39 ; $\mathrm{P}=0.2194$ ) was similar. The proportion of patients with Plt $\leq 1.0 \times 10^{10} / 1$ was higher in the TACE group (surgery: 33; TACE: 29; $\mathrm{P}=0.0109$ ) but that of patients with DCP $>400 \mathrm{mAU} / \mathrm{ml}$ was not different (surgery: 82 ; TACE: 38 ; $\mathrm{P}=0.6079$ ).

The 1-, 3-, and 5-year overall rates and median survival of patients who underwent surgery in the score $\leq 2$ group $(\mathrm{n}=152)$ were $95.3,79.1,62.9 \%$, and 75.5 months, respectively. For those who underwent TACE in the score $\leq 2$ group $(n=72)$, they were 92.7, 58.8, 37.8\%, and 48.0 months. The survival was significantly better in patients in the score $\leq 2$ group who underwent surgery $(\mathrm{P}=0.0094)$ (Fig. 5).

In contrast, the survival was not different between surgery $(n=34)$ and TACE $(n=21)$ in the score $\geq 3$ subgroup 
Table IV. Clinicopathologic characteristics of patients who underwent surgery or TACE.

\begin{tabular}{|c|c|c|c|}
\hline Variable & Surgery $(n=186)$ & TACE $(n=93)$ & P-value \\
\hline Age, years & $66.0(31.0-84.0)$ & $74.2(48.2-87.8)$ & $<0.0001$ \\
\hline \multicolumn{4}{|l|}{ Sex } \\
\hline Male & 153 & 69 & \multirow[t]{2}{*}{0.1153} \\
\hline Female & 33 & 24 & \\
\hline \multicolumn{4}{|l|}{$\mathrm{HCV}-\mathrm{Ab}$} \\
\hline Negative & 72 & 35 & \multirow[t]{2}{*}{0.8618} \\
\hline Positive & 114 & 58 & \\
\hline Tumor size on image, $\mathrm{cm}$ & $4.5(1.5-17.0)$ & $3.7(1.0-8.9)$ & 0.00018 \\
\hline Number of tumors on image & 2 (2-uncountable) & $4(2-11)$ & $<0.0001$ \\
\hline \multicolumn{4}{|l|}{ Tumor size + number of tumor } \\
\hline$\leq 8$ & 122 & 54 & \multirow[t]{2}{*}{0.2194} \\
\hline$>8$ & 64 & 39 & \\
\hline \multicolumn{4}{|l|}{ Platelet count, $/ \mu 1$} \\
\hline$\leq 1.0 \times 10^{5}$ & 33 & 29 & \multirow[t]{2}{*}{0.0109} \\
\hline$>1.0 \times 10^{5}$ & 153 & 64 & \\
\hline \multicolumn{4}{|l|}{$\mathrm{DCP}, \mathrm{mAU} / \mathrm{ml}$} \\
\hline$<400$ & 104 & 55 & \multirow[t]{2}{*}{0.6079} \\
\hline$\geq 400$ & 82 & 38 & \\
\hline \multicolumn{4}{|l|}{ Prognostic score } \\
\hline$\leq 2$ & 152 & 72 & \multirow[t]{2}{*}{0.3946} \\
\hline$\geq 3$ & 34 & 21 & \\
\hline
\end{tabular}

$\mathrm{HCV}-\mathrm{Ab}$, hepatitis $\mathrm{C}$ virus antibody; DCP, des- $\gamma$-carboxy prothrombin; TACE, transarterial chemoembolization.

(median survival: 29.2 vs. 31.1 months; 5-year survival rate: $25.6 \%$ vs. $18.0 \%$ for surgery vs. TACE, respectively, $\mathrm{P}=0.8723)$.

\section{Discussion}

The purpose of the present study was to derive a prognostic model of overall survival based on pre-treatment tumor and patient characteristics, and to identify the subgroup of patients with multinodular BCLC-B HCC who could benefit from liver resection. Indeed, we developed a prognostic score based on HCV-Ab status, pre-operative Plt, tumor status $(\mathrm{N}+\mathrm{S})$, and DCP level. According to this prognostic score, patients with a score $<2$ would benefit more from surgery than from TACE, which provides 5-year survival rate of approximately $30 \%$ or median survival of 30-39.7 months for patients with multinodular HCC in Child-Pugh class A $(7,9,19)$. In contrast, patients with a score $\geq 3$ would benefit from TACE as its outcomes were equivalent to those of surgery while being less invasive. Although $\mathrm{mVI}$ is the most widely recognized prognostic factor after liver resection $(13,14,16,17,20)$, it is impossible to determine pre-operatively. As our prognostic score was associated with the frequency of $\mathrm{mVI}$, it could also be useful for predicting its presence pre-operatively.

Some reports have shown that tumor size and number are prognostic factors $(12,16,21)$. Although either of these variables alone tended to be associated with the outcome of patients in univariate analyses, multivariate analysis showed

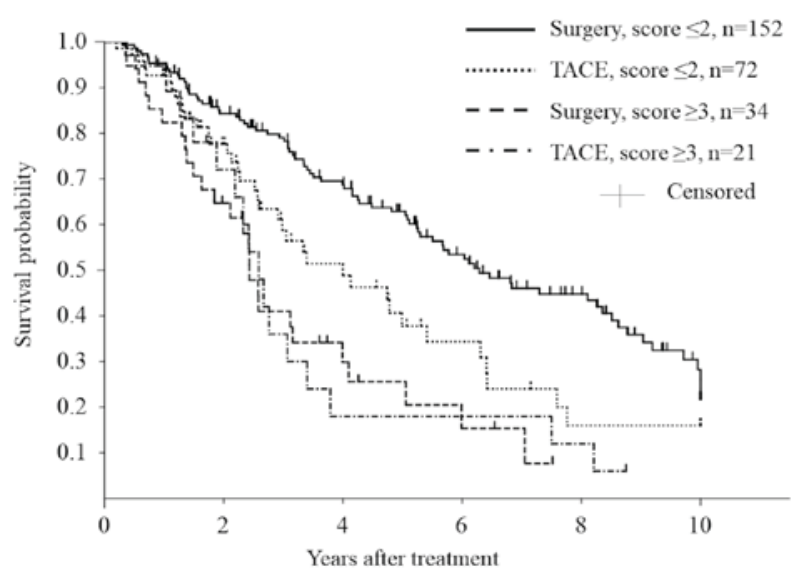

Figure 5. Overall survival of patients with Child-Pugh A in each subgroup according to treatment modalities. In patients with a score $\leq 2$, the survival of patients who underwent surgery (solid line) was significantly better than those underwent TACE (dotted line; $\mathrm{P}=0.0094$ ). By contrast, the survival was not different between surgery (dashed line) and TACE (dashed-dotted line) in the score $\geq 3$ subgroup. TACE, transarterial chemoembolization.

that $\mathrm{N}+\mathrm{S}$ had a stronger effect. Recently, we have shown that the mathematical product of maximum tumor size and number of tumors $(\mathrm{NxS})$ was an important prognostic factor after curative liver resection for HCC $(22)$. The 'metro ticket' $(23,24)$ and up-to-seven criteria (25) for liver transplantation for HCC, the subclassification (26) and NSP (27) score of BCLC-B HCC for surgery, and the 4 of $7 \mathrm{~cm}$ classification (19) of BCLC-B 
HCC for TACE all emphasize that both tumor size and number is a critical prognostic factor for several treatments for HCC. These results have shown that the sum of maximum tumor size and number of tumors reflect individual tumor characteristics more precisely than either variable by itself. We changed the cutoff point of $\mathrm{N}+\mathrm{S}$ and analyzed survival using univariate analyses in a step by step manner (data not shown). Because an $\mathrm{N}+\mathrm{S}>8$ had the strongest effect on survival in this analysis, we selected this cutoff point as a covariate in the Cox regression analysis. The up-to-seven criteria have been the most popular cutoff point in liver transplantation for HCC exceeding the Milan criteria. Although the optimal cutoff point could change in different cohorts, $\mathrm{N}+\mathrm{S}$ could be a stronger prognostic factor than tumor size or number by themselves.

Some studies have shown that DCP was a prognostic factor after liver resection for $\operatorname{HCC}(16,28)$ and that it correlated with an aggressive phenotype and mVI (29). Similar to these results, DCP was one of the independent prognostic factors for survival in this study.

Liver function is also an important prognostic factor after hepatic resection $(16,22)$. We demonstrated here that a Plt count $<10^{10} / 1$ was one such prognostic factor. Plt count and the aspartate aminotransferase to Plt ratio index have been reported as independent predictors of survival after liver resection for HCC $(30,31)$. These results may suggest that multiple HCCs and poor functional reserve are relative contraindications to liver resection, as Ishizawa et al (16) had reported earlier.

We acknowledge several limitations to this study. First, it was a retrospective study with a limited number of patients. Second, we could not compare the outcomes of patients underwent surgery and TACE with propensity score matching due to the small number of cases. Although the outcomes of patients who underwent liver resection were compared with those that underwent TACE in this study, bias due to patient selection may have been present. However, this study is potentially important for evaluating the effectiveness of liver resection for multinodular intermediate stage HCC as it excludes patients with large solitary tumors. Furthermore, the consensus report from the 5th Asia-Pacific Primary Liver Cancer Expert Meeting stated that randomization of patients into surgery or TACE is difficult because of patient risks and ethical reasons (32). In this situation, clinicians should make their treatment decisions after referring to previous retrospective analyses. Third, the study period of this analysis was relatively long. Treatment strategies and combinations of multimodality therapies could have changed during this long period; however, this could not be avoided as we attempted to identify prognostic factors in such a small cohort as BCLC-B HCC patients. Further investigation is needed to determine pre-treatment factors that can help clinicians select the appropriate treatment for each patient.

In conclusion, liver resection for selected patients with BCLC-B HCC is feasible and can promote long-term survival. $\mathrm{HCV}-\mathrm{Ab}$ status, preoperative Plt count, preoperative DCP level, and $\mathrm{N}+\mathrm{S}$ could be useful for patient selection.

\section{Acknowledgements}

The authors would like to thank Ms. Rie Akiyama (Department of Gastroenterological, Breast and Endocrine
Surgery, Yamaguchi University Graduate School of Medicine, Yamaguchi, Japan) for her cooperation during data collection.

\section{Funding}

No funding was received.

\section{Availability of data and materials}

The datasets used and/or analyzed during the current study are available from the corresponding author on reasonable request.

\section{Authors' contributions}

SM, KS, YoT, YuT, HM, SKa, STo, MI, NS, STa, HW, SKo and ISaeki collected, analyzed and interpreted the patients' data. TU, HE, MS, ISakaida and HN conceived and designed the present study. All authors have read and approved the final manuscript.

\section{Ethics approval and consent to participate}

The present study was approved by the Institutional Review Boards of each of the three institutes in which data was obtained (Yamaguchi University Hospital, Osaka International Cancer Institute and Osaka University Hospital; protocol no. H29-093) and was conducted in accordance with the ethical standards of the 1964 Declaration of Helsinki. The requirement for informed consent was waived as this was a retrospective cohort study.

\section{Patient consent for publication}

Not applicable.

\section{Competing interests}

The authors declare that they have no conflict of interest.

\section{References}

1. Ferlay J, Soerjomataram I, Dikshit R, Eser S, Mathers C, Rebelo M, Parkin DM, Forman D and Bray F: Cancer incidence and mortality worldwide: Sources, methods and major patterns in GLOBOCAN 2012. Int J Cancer 136: E359-E386, 2015.

2. Colvin H, Mizushima T, Eguchi H, Takigushi S, Doki Y and Mori M: Gastroenterological surgery in Japan: The past, the present and the future. Ann Gastroenterol Surg 1: 5-10, 2017.

3. Seto Y, Kakeji Y, Miyata H and Iwanaka T: National Clinical Database (NCD) in Japan for gastroenterological surgery: Brief introduction. Ann Gastroenterol Surg 2: 80-81, 2017.

4. Kaneko H, Otsuka Y, Kubota Y and Wakabayashi G: Evolution and revolution of laparoscopic liver resection in Japan. Ann Gastroenterol Surg 1: 33-43, 2017.

5. Kobayashi S, Fukui K, Takeda Y, Nakahira S, Tsujie M, Shimizu J, Miyamoto A, Eguchi H, Nagano H, Doki Y, et al: Short-term outcomes of open liver resection and laparoscopic liver resection: Secondary analysis of data from a multicenter prospective study (CSGO-HBP-004). Ann Gastroenterol Surg 2: 87-94, 2018.

6. Bruix J and Sherman M; American Association for the Study of Liver Diseases: Management of hepatocellular carcinoma: An update. Hepatology 53: 1020-1022, 2011.

7. Choi SH, Choi GH, Kim SU, Park JY, Joo DJ, Ju MK, Kim MS Choi JS, Han KH and Kim SI: Role of surgical resection for multiple hepatocellular carcinomas. World J Gastroenterol 19: 366-374, 2013. 
8. Ho MC, Huang GT, Tsang YM, Lee PH, Chen DS, Sheu JC and Chen $\mathrm{CH}$ : Liver resection improves the survival of patients with multiple hepatocellular carcinomas. Ann Surg Oncol 16: 848-855, 2009

9. Kim JY, Sinn DH, Gwak GY, Choi GS, Saleh AM, Joh JW, Cho SK, Shin SW, Carriere KC, Ahn JH, et al: Transarterial chemoembolization versus resection for intermediate-stage (BCLC B) hepatocellular carcinoma. Clin Mol Hepatol 22: 250-258, 2016.

10. Bolondi L, Burroughs A, Dufour JF, Galle PR, Mazzaferro V, Piscaglia F, Raoul JL and Sangro B: Heterogeneity of patients with intermediate (BCLC B) hepatocellular carcinoma: Proposal for a subclassification to facilitate treatment decisions. Semin Liver Dis 32: 348-359, 2012.

11. Chang WT, Kao WY, Chau GY, Su CW, Lei HJ, Wu JC, Hsia CY, Lui WY, King KL and Lee SD: Hepatic resection can provide long-term survival of patients with non-early-stage hepatocellular carcinoma: extending the indication for resection? Surgery 152 : 809-820, 2012

12. Delis SG, Bakoyiannis A, Tassopoulos N, Athanassiou K, Kelekis D, Madariaga J and Dervenis C: Hepatic resection for hepatocellular carcinoma exceeding Milan criteria. Surg Oncol 19: 200-207, 2010.

13. Liu W, Wang K, Bao Q, Sun Y and Xing BC: Hepatic resection provided long-term survival for patients with intermediate and advanced-stage resectable hepatocellular carcinoma. World J Surg Oncol 14: 62, 2016.

14. Ng KK, Vauthey JN, Pawlik TM, Lauwers GY, Regimbeau JM, Belghiti J, Ikai I, Yamaoka Y, Curley SA, Nagorney DM, et al: Is hepatic resection for large or multinodular hepatocellular carcinoma justified? Results from a multi-institutional database. Ann Surg Oncol 12: 364-373, 2005

15. Torzilli G, Belghiti J, Kokudo N, Takayama T, Capussotti L, Nuzzo G, Vauthey JN, Choti MA, De Santibanes E, Donadon M, et al: A snapshot of the effective indications and results of surgery for hepatocellular carcinoma in tertiary referral centers: is it adherent to the EASL/AASLD recommendations? An observational study of the HCC East-West study group. Ann Surg 257: 929-937, 2013.

16. Ishizawa T, Hasegawa K, Aoki T, Takahashi M, Inoue Y, Sano K, Imamura H, Sugawara Y, Kokudo N and Makuuchi M: Neither multiple tumors nor portal hypertension are surgical contraindications for hepatocellular carcinoma. Gastroenterology 134: 1908-1916, 2008.

17. Kim PT, Jang JH, Atenafu EG, Fischer S, Greig PD, McGilvray ID, Wei AC, Gallinger S and Cleary SP: Outcomes after hepatic resection and subsequent multimodal treatment of recurrence for multifocal hepatocellular carcinoma. Br J Surg 100: 1516-1522, 2013.

18. Nagano H, Kishimoto S, Kobayashi S, Marubashi S, Eguchi H Takeda Y, Tanemura M, Tomimaru Y, Noda T, Umeshita K, et al: A safe protocol of intermittent hilar vascular clamping for hepatic resection in cirrhosis. Hepatogastroenterology 56: 1439-1444, 2009.

19. Yamakado K, Miyayama S, Hirota S, Mizunuma K, Nakamura K, Inaba Y, Yamamoto S, Matsuo K, Nishida N, Aramaki T, et al: Prognosis of patients with intermediate-stage hepatocellular carcinomas based on the Child-Pugh score: Subclassifying the intermediate stage (Barcelona Clinic Liver Cancer stage B). Jpn J Radiol 32: 644-649, 2014

20. Rodríguez-Perálvarez M, Luong TV, Andreana L, Meyer T, Dhillon AP and Burroughs AK: A systematic review of microvascular invasion in hepatocellular carcinoma: diagnostic and prognostic variability. Ann Surg Oncol 20: 325-339, 2013.
21. Truant S, Boleslawski E, Duhamel A, Bouras AF, Louvet A, Febvay C, Leteurtre E, Huet G, Zerbib P, Dharancy S, et al: Tumor size of hepatocellular carcinoma in noncirrhotic liver: A controversial predictive factor for outcome after resection. Eur J Surg Oncol 38: 1189-1196, 2012.

22. Tokumitsu Y, Tamesa T, Matsukuma S, Hashimoto N, Maeda Y, Tokuhisa Y, Sakamoto K, Ueno T, Hazama S, Ogihara H, et al: An accurate prognostic staging system for hepatocellular carcinoma patients after curative hepatectomy. Int J Oncol 46: 944-952, 2015.

23. Llovet JM, Schwartz M and Mazzaferro V: Resection and liver transplantation for hepatocellular carcinoma. Semin Liver Dis 25: 181-200, 2005.

24. Majno P and Mazzaferro V: Living donor liver transplantation for hepatocellular carcinoma exceeding conventional criteria: Questions, answers and demands for a common language. Liver Transpl 12: 896-898, 2006.

25. Mazzaferro V, Llovet JM, Miceli R, Bhoori S, Schiavo M, Mariani L, Camerini T, Roayaie S, Schwartz ME, Grazi GL, et al: Predicting survival after liver transplantation in patients with hepatocellular carcinoma beyond the Milan criteria: A retrospective, exploratory analysis. Lancet Oncol 10: 35-43, 2009

26. Wada H, Eguchi H, Noda T, Ogawa H, Yamada D, Tomimaru Y, Tomokuni A, Asaoka T, Kawamoto K, Gotoh K, et al: Selection criteria for hepatic resection in intermediate-stage (BCLC stage B) multiple hepatocellular carcinoma. Surgery 160: 1227-1235, 2016.

27. Zhang YF, Zhou J, Wei W, Zou RH, Chen MS, Lau WY, Shi M and Guo RP: Intermediate-stage hepatocellular carcinoma treated with hepatic resection: The NSP score as an aid to decision-making. Br J Cancer 115: 1039-1047, 2016.

28. Shimada M, Takenaka K, Fujiwara Y, Gion T, Kajiyama K, Maeda T, Shirabe K and Sugimachi K: Des-gamma-carboxy prothrombin and alpha-fetoprotein positive status as a new prognostic indicator after hepatic resection for hepatocellular carcinoma. Cancer 78: 2094-2100, 1996.

29. Koike Y, Shiratori Y, Sato S, Obi S, Teratani T, Imamura M, Yoshida H, Shiina S and Omata M: Des-gamma-carboxy prothrombin as a useful predisposing factor for the development of portal venous invasion in patients with hepatocellular carcinoma: A prospective analysis of 227 patients. Cancer 91: 561-569, 2001.

30. Amano H, Tashiro H, Oshita A, Kobayashi T, Tanimoto Y, Kuroda S, Tazawa H, Itamoto T, Asahara $\mathrm{T}$ and Ohdan $\mathrm{H}$ : Significance of platelet count in the outcomes of hepatectomized patients with hepatocellular carcinoma exceeding the Milan criteria. J Gastrointest Surg 15: 1173-1181, 2011.

31. Cheng J, Zhao P, Liu J, Liu X and Wu X: Preoperative aspartate aminotransferase-to-platelet ratio index (APRI) is a predictor on postoperative outcomes of hepatocellular carcinoma. Medicine (Baltimore) 95: e5486, 2016.

32. Ho MC, Hasegawa K, Chen XP, Nagano H, Lee YJ, Chau GY, Zhou J, Wang CC, Choi YR, Poon RT and Kokudo N: Surgery for intermediate and advanced hepatocellular carcinoma: A consensus report from the 5 th asia-pacific primary liver cancer expert meeting (APPLE 2014). Liver Cancer 5: 245-256, 2016.

This work is licensed under a Creative Commons Attribution-NonCommercial-NoDerivatives 4.0 International (CC BY-NC-ND 4.0) License. 